\title{
Biologically Important Schiff Bases and Their Transition Metal Complexes
}

Riya Datta* and Ramya $\mathrm{V}^{\dagger}$

\begin{abstract}
:
Transition metal complexes with different ligand systems have been developed. Majority of them are derived from heteroaromatic cycles and Schiff bases of variety of aromatic aldehydes, diketones with amino acids, polyamines, $\mathrm{N}$-aromatic cycles and ethylenediamines. Metal complexes of Schiff bases are used as polymers, dyes and in various biological systems. They show antimicrobial activity and can be used as suitable drug to treat bacterial and fungal infections. Most of the $\mathrm{Cu}, \mathrm{Ni}$ and Co complexes are also capable of binding and cleaving DNA.
\end{abstract}

Keywords: Transition metals, amino acids, Schiff bases, antimicrobial activity, DNA cleavage

\section{Introduction}

Metal complexes have always intrigued chemists since their inception. Though they would have questioned elementary bonding theory in their infancy, today their applications are

* Department of Chemistry, Christ University, Bangalore-560029, riya.datta@christuniversity.in

t Department of Chemistry, Christ University, Bangalore-560029, ramya.v@christuniversity.in 
multifarious. A paradigm shift was experienced in medicinal chemistry, which is based on organic compounds, due to serendipitous discovery of cis-platin's antitumor property. Since then, chemists are engrossed in discovering novel metal complexes with medicinal properties to tackle diseases which always battle with human beings to gain an upper hand. Metal coordinated ligand's 3-dimensional orientation helps in specific molecule recognition. Thus the interaction of metal complexes with biomolecules is different when compared to that of classic drugs. Today gold and platinum complexes are already in the market serving as antiarthritic and antitumor drugs respectively, yet indepth structure activity relationship (SAR) investigations are needed, to develop metal based drugs with improved pharmacological properties. Ligands can also be tailored for enhanced specificity. Diversity of transition metal complexes with medicinal properties are being reported, among which many are centered at metal complexes derived from Schiff bases. This is because of their easy synthesis, good donor abilities and established medicinal properties. Schiff base compounds find application as antibacterial, antifungal and antitumor drugs.

\subsection{History of metallodrugs}

Barnett Rosenberg, a biophysicist in Michigan State University, accidently discovered cis-platin. He was studying the effect of applied electric field on the growth of E.Coli cells, in order to prove that spindle fiber formation gets perturbed during cell division. Instead he observed cell elongation without cell division. Later he diagnosed that platinum from the electrodes, which he used to apply electric field, had dissolved in the buffer containing ammonium chloride forming $\left[\mathrm{Pt}\left(\mathrm{NH}_{3}\right)_{2} \mathrm{Cl}_{2}\right]$ complex, which caused cell elongation.

The in vivo studies of the compound showed necrosis of tumor in rats. This initiated cis-platin, a metal complex to be used as a drug in the treatment of cancer and the search for new complexes with better pharmacological properties began and is continuing [1]. 


\subsection{Theory of metal complex toxicity}

$\mathrm{Ab}$ initio studies on drugs have proved that, lipophilic character of drugs plays an important role in its medicinal property, as phospholipid bilayered cell membrane is selectively permeable. One has to consider this property while developing metal complex based drugs. According to overtone's concept of cell permeability, the lipophilic cell membrane permits the passage of only lipid soluble materials, which makes liposolubility as an important factor for controlling the microbial activity. This has been emphasized in Tweedy's chelation theory [2].

\subsection{Chelation theory}

On chelation of ligand to the metal, the polarity of the metal ion is reduced to a great extent due to the overlap of the ligand orbital with the metal orbital and there is partial sharing of the positive charge of the metal ion with donor atom and increases the delocalization of pi-electrons over the chelate ring. Thus chelation enhances the lipophilic character of the central metal atom, which subsequently favors its permeation through the lipid layers of the cell membrane and enhances the penetration of the complexes into the lipid membrane, thereby blocking the metal binding sites in the enzymes of the microorganism. Many in vitro studies have shown the inhibition of enzyme activities in the presence of transition metal complexes [3], [4].

Inhibition of enzymes can disturb the respiration process, cell homeostasis and thus block the synthesis of proteins which restricts the further growth of the organisms. Moreover metal complexes easily undergo redox reactions and ligand substitutions, which allow them to participate in biological redox chemistry and interact with bio-molecules [5], [6].

Many transition metal complexes with different ligand systems have been developed, which show antimicrobial, antitumor (DNA binding and cleavage) properties, majority of them being derived from heteroaromatic cycles and Schiff bases of variety of aromatic aldehydes and amines. 


\section{Schiff Bases}

The biological activity of chelating ligands having $\mathrm{N}, \mathrm{S}$ and $\mathrm{O}$ as donor atoms have been studied due to their different metal binding modes. The metal ions alter or enhance the activity of the biologically active compounds on complexation [7]. Copper complexes of iminodiacetic acid and diimines have the ability of cleaving double-stranded DNA, by both oxidative and hydrolytic cleavage mechanisms [8].

\section{Schiff base with Heterocyclic Group}

Many synthetic compounds with quinoline derivatives were found to have pharmacological properties [9]. Drugs containing quinoline are known to act as antimalarials [10] [11]. $\mathrm{Co}(\mathrm{II})$ and $\mathrm{Ni}(\mathrm{II})$ complexes of Quinolino Schiff bases were also found to have antimicrobial properties[12].

Schiff base and their complexes have showed appreciable antibacterial and antifungal activity. Tumor growth is also found to be inhibited by some Schiff base complexes. Cobalt complexes of reduced $\mathrm{N}, \mathrm{N}^{\prime}$-o-Phenylene bis (salicylideneimine) have showed significant growth inhibition of yeasts and fungi of the genus Scedosporium[13].

$\mathrm{Cu}(\mathrm{II}), \mathrm{Ni}(\mathrm{II})$ and $\mathrm{VO}(\mathrm{II})$ complexes of Schiff base ligands derived from indole derivatives have showed significant antimicrobial activity against pathogens in comparison to the ligands which showed no activity prior complexation to metals[14]. Co(II), Ni(II), $\mathrm{Cu}(\mathrm{II}), \mathrm{Mn}(\mathrm{II}), \mathrm{Fe}(\mathrm{II})$ complexes of isatin derivatives have been screened for their in-vitro antibacterial activities[15]. Complexes of various Schiff base ligands derived from aminoantipyrine had high antimicrobial activities and were found to cleave DNA [16-19].

\section{Schiff Base Analogues of Amino Acids}

Schiff bases behave as chelating ligands in coordination chemistry [20]. They are also used in catalysis, anti-oxidative activity and as 60 
medicines [21]. Amino acid Schiff bases are very effective metal ligands and their metal complexes act as models for numerous biological systems [22]. These are also involved in numerous biochemical reactions which are catalyzed by enzymes [23]. Many of them serve as models for the study of pyridoxal (PLP)-amino acid Schiff bases which are involved in many metabolic pathways. [25].

Amino acid Schiff bases and their first row transition metal complexes exhibit antifungal, antibacterial, antiviral and antitubercular activity [24]. Most of these complexes interact with DNA through intercalative binding modes [26].

2-nitrobenzaldehyde-glycine and 2-nitrobenzaldehyde methionine Schiff base was coordinated with $\mathrm{Co}(\mathrm{II}), \mathrm{Ni}(\mathrm{II})$ and $\mathrm{Cu}$ (II) [27]. The metal chelates possessed reasonable antimicrobial potential.

Indole derivatives are known to show variety of biological activities such as CNS depressant, anticancerous, antibiotic, antihistamine, anticonvulsants, etc [28]. Antimicrobial activity of unsymmetrical Schiff bases of indole 3-carboxaldehyde with different amino acids like histidine, glutamic acid, aspartic acid, valine and leucine and amino acid analogues such as 2aminophenol, 2-aminophenol-4-sulphonic acid, 1-amino-2naphthol-4 sulphonic acid have been studied[29]. Co(II), Ni(II) and $\mathrm{Cu}$ (II) complexes of Schiff base ligand formed from glycylglycine and indole-3-carboxaldehyde were also investigated[30]. The $\mathrm{Cu}$ (II) complexes were found to possess higher bacterial and fungal properties than the other metal complexes and ligands.

\section{DNA-metal Complex Interactions}

It is now well established that DNA is the master molecule behind cell homeostasis and regulation. In tumor cells, cell division is uncontrolled leading to cancer. Various biological experiments suggest that DNA is the primary intracellular target of an anticancer drug because the interaction between this molecule and DNA can cause DNA damage in cancer cells blocking the irregular division of cancer cells and resulting in apoptosis [31], [32]. 
Cis-platin suffers from the major draw backs of nephrotoxicity, neurotoxicity and intravenous administration [33]. These drawbacks have stimulated an extensive search for other tumorinhibiting complexes of bioessential transition metals like copper and iron with improved pharmacological properties. Investigations are going on for molecularly targeted metal-based anticancer drugs with high specificity versus cytotoxic and broad-spectrum agents.

The interaction of metal complexes with DNA is the most studied aspect of antitumor metal drugs because only then a chemist will be able to develop better drugs with enhanced medicinal properties. So the SAR is of first importance. The possible metal complex-DNA interactions are DNA binding and DNA cleavage.

\subsection{DNA binding}

Metal complexes can bind to DNA in the following ways:

a. Coordination of the DNA bases to the metal atom

Purines and pyrimidines are the building blocks of DNA. The nitrogen atom in these compounds is a good donor towards transition metals. This type of interaction can happen through the major or the minor groove of DNA [3436].

b. Intercalation between the stacked base pairs of DNA from the major groove side.

Metal complexes with ligands such as fused ring organic heterocycles or polyaromatic planar hydrocarbons can efficiently lodge themselves in between the stacked base pairs [37].

c. Electrostatic interaction with DNA

DNA is a negatively charged molecule due to the presence of phosphate groups. This inherent property of DNA is utilized in electrophoresis - a separation technique. The chances of electrostatic interaction of ligands with oxygen of phosphate groups or with nitrogen of the bases are high. Hydrogen bonding between the coordinated ligand and the 
oxygen of the sugar phosphate back bone is also possible [38-40].

The two modes of binding ( $a \& b)$ largely depend on the nature of conformation of DNA and structural properties, orientation of the ligands of metal complexes [25] [41] [42].

Some complexes show high avidity towards DNA. This may be due to synergistic contribution of all of the three $(a, b \& c)$ mentioned above and the best illustration in this case is $\mathrm{Ru}(\mathrm{phen})_{3}$ complex, as it has high affinity towards DNA and binds by all the above said modes. One planar heterocyclic ring can intercalate with DNA, while the other can enter into a hydrophobic interaction with the minor groove and also involve in $\mathrm{H}$-bonding with phosphate moieties of the sugar back bone. Such complexes are robust models, to design and develop metal complexes with desired properties [43].

Binding of the complexes can cause physical alterations like conversion of the super coiled form of DNA to the relaxed form. Many investigators have proposed that, on binding DNA, many metal complexes are found to inhibit the enzymes involved in DNA duplication, like topoisomerases (invitro), which may stall the DNA duplication in tumor cells. [44-47].

\subsection{DNA cleavage}

The second type of DNA-metal complex interaction is cleavage of DNA. DNA cleavage is an important property of transition metal complex based antitumor drugs. As these complexes exhibit slicing of DNA analogous to biological DNA cleavers - Nucleases, they are called Artificial Nucleases.

\subsubsection{Types of cleavage}

\subsubsection{Redox cleavage}

Metal complexes of copper can easily undergo redox reactions and generate reactive oxygen species (ROS) like superoxides, hydroxyl radicals or singlet oxygen. These oxidizing intermediates can cleave DNA. However generation of these reactive intermediates can be assisted chemically or in presence of light. 
In chemically assisted DNA cleavage, oxidants like hydrogen peroxide can interact with copper complexes to generate hydroxyl radicals which in turn oxidize nucleotides of DNA [48 - 50].

In photo chemically assisted DNA cleavage, metal complexes are photo chemically excited to their higher energy states, which suffers an energy transfer to the triplet state, which can activate oxygen from its stable triplet state ${ }^{3} \sum_{\mathrm{g}}$ to its toxic singlet state ${ }^{1} \Delta_{\mathrm{g}}$ [51].

Various metal complexes are investigated for their DNA binding and cleaving properties. Copper complexes of different amino acids like alanine [52], threonine [53], l-leucine/isoleucine 54], phenylalanine [55], proline [56], methycystein [57], glutamine [58] have been synthesized and DNA cleavage properties are studied. It is proposed that DNA is cleaved by the reactive oxygen species $\mathrm{OH} \bullet$, generated in the presence of $\mathrm{H}_{2} \mathrm{O}_{2}$ [44], [59], [60].

Transition metal complexes of Schiff bases of different aromatic, heteroaromatic aldehydes like, salicylaldehyde [61], pyridine carboxaldehyde [62], indole carboxaldehyde [63], oxo-quinoline-3carbaldehyde [64] and amines like 2-aminobenzothiazole [65], aminomethylthiophene [66] and antipyrine [16], [18] were synthesized and their DNA binding cleavage abilities have been studied.

\subsubsection{Hydrolytic cleavage}

Coordination of metal complex to sugar phosphate backbone can cause hydrolysis of phosphodiester bond by polarizing P-O bond. Coordinated nucleophile can also react with phosphate groups leading to DNA cleavage [75] [76]. The effect of extended fused cycles [37], functional group substitution of ligands [70], planarity of cycles [77], [78], chirality [79] and orientation of ligands on metal assisted DNA binding have been investigated[24].

\section{Schiff Bases of Different Amino Acids}

Schiff bases of different amino acids like valine have been synthesized and their DNA binding and cleavage abilities have 64 
been investigated [24], [44], [67-73], prioritizing selective DNA binding and site specific DNA cleavage [74].

Fused planar aromatic cycles are studied for DNA cleavage abilities worldwide because planar aromatic cycles show good DNA binding ability. Copper is a good lewis acid and can take part in redox chemistry and efficient in generating $\mathrm{ROS}$ like $\mathrm{O}_{2}, \mathrm{OH} \bullet, \mathrm{O}_{2}$ which can cleave DNA [48-58].

\section{Conclusion}

Metal complexes are next generation drugs. Intense and dedicated research is required for deciphering the metal complex's mechanism behind pharmacological properties and interactions with biological systems. Toxicity, metabolism and excretion of metallodrugs have to be studied thoroughly. Novel metal complexes may find place in DNA finger printing and in spectroscopic probing of biomolecules in future. A ray of hope is that these metal complex drugs may tackle the issue of multi drug resistance of pathogens and can be an efficient antitumor drug.

\section{Acknowledgement}

The authors are thankful to Christ University for financial assistance. The authors also thank Prof. Akhil Ranjan Chakravarty and Dr Santanu Mukherjee of IISc Bangalore for constant support.

\section{References}

[1] Bertini,gray,lippard,valentine, Bioinorganic Chemistry, Viva Books Pvt . Itd, Revised Ed:2007.

[2] Fehmi N et al.,"Sulphur bonded Palladium (II) and Platinum (II) complexes of Biologically potent Thioamides," Phosphorus, Sulphur, Silicon and the Related Elements," TEF Online, vol.128 (1),pp.1-9, 1998.

[3] E.H.R.Tomi et al., "Synthesis and Characterization of New Amino Acid-Schiff Bases and Studies their Effects on the Activity of ACP, PAP and NPA Enzymes (In Vitro)" E.J.Chem., vol. 9(2), pp.962-969, 2012.

[4] Q.Zhang et al., "Schiff base transition metal complexes as novel inhibitors of xanthine oxidase". E.Pub, vol.43 (4), pp.862-871, 2007. 
[5] Dharmaraj.N, "Ruthenium (II) complexes containing bidentate Schiff bases and their antifungal activity," Trans.Met.Chem., Vol.26, pp.105109, 2001.

[6] Farrell.N, "Recent developments in the chemistry of, 1,3,2diazaborolines-(2,3-dihydro-1H-1,3 diazaboroles," Coord. Chem. Rev., vol.232 (1-2), pp.1-31, 2007.

[7] M.D.Pandey et al., "Synthetic, Spectral, Structural and Antimicrobial Studies of Some Schiff Bases 3-d Metal Complexes," Rus.J.Inorg.Chem., vol.56, no.11, pp.1757-1764, 2011.

[8] B. Selvakumar et al., "Structures, Spectra, and DNA Binding Properties of Mixed Ligand Copper(II) Complexes of Iminodiacetic Acid: The Novel Role of Diimine Conformation and Co-ligands on DNA Hydrolytic and Oxidative Double Strand DNA Cleavage Certain Diiminies and Iminodiacetic Acid Bound to Calf Thymus DNA," J. Inorg. Biochem., Vol.100, pp.316-321, 2006.

[9] Bringmann G., "The total synthesis of streptonigrin and related antitumor antibiotic natural products". Tetrahedron, vol.60 (16), pp.3539-3574, 2004.

[10]O'Neill et al., "4-aminoquinolines-past, present and future: a chemical perspective". Pharmacology \& Therapeutics, vol.1, pp.77-82, 1998.

[11]Foley $\mathrm{M}$ et al., "Quinoline antimalarials: mechanisms of action and resistance and prospects for new agents". Pharmacology $\mathcal{E}$ Therapeutics," vol.79 (1), pp.55-87, 1998.

[12] Basavaraju et al., "Transition metal complexes of Quinoline [3, 2b]benzodiazepine and quinoline [3,2-b]benzoxazepine: Synthesis, Characterisation and Antimicrobial studies". Bioinorg.ChemEAppl., Sept 2007 Vol.2007, Article ID 42587, 6 pages.

[13]G. Bouet et al., "Synthesis, characterization and antifungal activity of a series of Cobalt(II) and Nickel(II) complexes with ligands derived from reduced N, N'-o-Phenylenebis(Salicylideneimine)," Transt.Met.Chem., vol.33, pp.511-516, 2003.

[14]Tudor Rosu, et. al., "Synthesis and characterization of some new complexes of $\mathrm{Cu}(\mathrm{II}), \mathrm{Ni}$ (II) and $\mathrm{V}(\mathrm{IV})$ with Schiff base derived from indole-3-carboxaldehyde. Biological activity on prokaryotes and eukaryotes," Eur.J.Med.Chem., vol.53, pp.380-389, 2012.

[15]Kulkarni et al., "Electrochemical properties of some Transition metal complexes: Synthesis, Characterization and In-vitro antimicrobial studies of $\mathrm{Co}(\mathrm{II}), \mathrm{Ni}(\mathrm{II}), \mathrm{Cu}(\mathrm{II}), \mathrm{Mn}(\mathrm{II})$ and $\mathrm{Fe}(\mathrm{III})$ Complexes," Int. J. Electrochem. Sci., vol.4, pp.717-729, 2009. 
[16]N.Raman et al., "Comparison of the Cleavage Ability of Metal Complexes Containing Tetradentate Schiff Bases," Rus.J.Inorg Chem., Vol. 53, No. 2, pp. 213-219 2008.

[17]N.Raman et al., "Design, Synthesis, Spectroscopic Characterization, Biological Screening, and DNA Nuclease Activity of Transition Metal Complexes Derived from a Tridentate Schiff Base," Rus.J.Coord.Chem., Vol. 34, No. 6, pp. 400-406, 2008.

[18]N.Raman et al., "Molecular Designing, Structural Elucidation, and Comparison of the Cleavage Ability of Oxovanadium(IV) Schiff Base Complexes," Rus.J.Coord.Chem., Vol. 33, No. 1, pp. 7-11, 2007.

[19]J.Joseph et al., "Synthesis, characterization and antimicrobial activities of copper complexes derived from 4-aminoantipyrine derivatives," J. Saud. Chem. Soc, April 2011, doi:10.1016/ j.jscs.2011.04.007

[20]K. R. Grunwald et al., "Pyridazine-Based Ligands and Their Coordinating Ability towards First-Row Transition Metals," Eur. J. Inorg. Chem, vol.15, pp.2297-2305, 2010.

[21] Deligönül.N et al., "Synthesis and Characterization, Catalytic, Electrochemical and Thermal Properties of Tetradentade Schiff Base Complexes," Trans. Met. Chem. vol.31, pp.920-929, 2006.

[22] V.B.Badwaik et al., "Transition metal complexes of a Schiff base: synthesis, characterization, and antibacterial studies,"

J. Coord. Chem., vol.62, no.12, pp.2037-2047, 2009.

[23]K.B.Gudasi et al., "X-ray Crystal Structure of the N-(2-hydroxy-1naphthalidene) phenylglycine Schiff Base. Synthesis and Characterization of its Transition Metal Complexes," Trans. Met. Chem., vol.31 no.5, pp.580-585, 2012.

[24]L. Li et al., "A copper (II) complex of the Schiff base from L-valine and 2-hydroxy-1-naphthalidene plus 1, 10-phenanthroline: synthesis, crystal structure, and DNA interaction," Trans. Met. Chem., vol.37, pp.175-182 2012.

[25]Y.Matsuo et al., "Formation of Schiff Bases of Pyridoxal Phosphate. Reaction with Metal Ions," J. Am. Chem. Soc., vol.79 no.8, pp. 20112015, 1957.

[26]G.S.Kurdekar et al., "Synthesis, characterization, antibiogram and DNA binding studies of novel $\mathrm{Co}(\mathrm{II}), \mathrm{Ni}(\mathrm{II}), \mathrm{Cu}(\mathrm{II})$ and $\mathrm{Zn}$ (II) complexes of Schiff base ligands with quinoline core," Med. Chem. Res., vol.20, pp.421-429, 2011.

[27]B. K. Singh et al., "Synthesis characterization and biological activity of transition metal complexeswith Schiff bases derived from 2nitrobenzaldehydewith glycine and methionine," Spectrochim. Acta Part A, vol.94, pp.143-151, 2012. 
[28] Pandeya et al., "indole, a versatile nucleus in pharmaceutical field"Int.J.Curr.Pharma.Res., vol.1, no.5, pp.1-17, 2010.

[29]A.K.Mishra, "Synthesis, characterization and biological activity of Schiff base analogues of indole-3-carboxaldehyde," Eur. J. Inorg. Chem., vol.43, pp.160-165, 2008.

[30]M.S.Nair et al., "Synthesis, characterization and biological studies of some $\mathrm{Co}(\mathrm{II}), \mathrm{Ni}(\mathrm{II})$ and $\mathrm{Cu}(\mathrm{II})$ complexes derived from indole-3carboxaldehyde and glycylglycine as Schiff base ligand," Arab.J.Chem., vol.3, pp.195-204, 2010.

[31]B.U Nair et al., "Oxidative DNA cleavage mediated by a new copper (II) terpyridine complex: Crystal structure and DNA binding studies," J.Inorg.Biochem., vol.12, pp.2299-2307, 2005.

[32]Y.M.Liu et al., "DNA Binding and cleavage activity of $\mathrm{Ni}(\mathrm{II})$ complex with all-trans retinoic acid," J.Inorg.Biochem., vol. 100, no. 10, pp. 1685-1691, 2006.

[33]Lippard et al.,"New metal complexes as potential therapeutics," Curr. Opin. Chem. Biol., vol.7 no.4, pp.481-489, 2003.

[34]P. Sharma et al, "Coordination Modes of a Schiff Base Pentadentate Derivative of 4-Aminoantipyrine with Cobalt (II), Nickel(II) and Copper(II) Metal Ions: Synthesis, Spectroscopic and Antimicrobial study," Molecules, vol.14, pp.174-190, 2009.

[35]B.U.Nair et al., "Interaction of DNA with [Cr(Schiff base)(H2O)2]ClO4," J.Photochem.Photobiol B: Biology, vol.86, pp.272278, 2007.

[36]S.M.Zingde et al., "Carbohydrate-conjugate heterobimetallic complexes: synthesis, DNA binding studies, artificial nuclease activity and in vitro cytotoxicity," Carbohydrate Research, vol.346, pp.2886-2895, 2011.

[37]K.Abdi et al, "Mononuclear copper(II) complex with terpyridine and an extended phenanthroline base, $[\mathrm{Cu}(\mathrm{tpy})(\mathrm{dppz})] 2+$ : Synthesis, crystal structure, DNA binding and cytotoxicity," Polyhedron, vol.31, pp.638-648 2012.

[38]M.Palaniandavar et al., "DNA binding and cleavage properties of certain tetra ammine ruthenium (II) complexes of modified 1,10phenanthrolines - effect of hydrogen-bonding on DNA-binding affinity," J.Inorg.Biochem., vol.98 pp. 219-230, 2004.

[39]D.Wang et al., "A ternary copper(II) complex for supramolecular assembly with double helices: synthesis, crystal structure, DNAbinding and DNA-cleavage properties," Trans. Met. Chem., vol.36, pp.289-295, 2011. 
[40]R.Zeng et al., "Synthesis, characterization and DNA interaction of copper (II) complexes with Schiff base ligands derived from 2pyridinecarboxaldehyde and polyamines," Inorg.Chem. Commu., vol.13, pp.1421-1424, 2010.

[41]N. Raman et al., "Probing the DNA-binding behavior of tryptophan incorporating mixed-ligand complexes" Monatsh chem., DOI: 10.1007/s00706-012-0718-4, 2012.

[42]Z.Liu et al., "DNA-binding, antioxidant activity and solid-state fluorescence studies of copper(II), zinc(II) and nickel(II) complexes with a Schiff base derived from 2-oxo-quinoline-3-carbaldehyde," Trans. Met. Chem., vol.36, pp.489-498, 2011.

[43]A.K. Das, Bioinorganic chemistry, Books and Allied Pvt ltd, Revised Ed: 2008.

[44]Ingo Ott, Ronald Gust, "Non Platinum Metal Complexes as Anticancer Drugs," Archiv der Pharmazie, vol.340, no.3, 117-126, 2007.

[45]P.J.Dyson et al., "Development of organometallic (organo-transition metal) pharmaceuticals," App.Organomet.Chem, vol.19, no.1, pp.1$10,2005$.

[46]A.K.Kondapi et al., "Inhibition of Topoisomerase II Catalytic Activity by Two Ruthenium Compounds: A Ligand-Dependent Mode of Action," Biochemistry, vol.38, no.14, pp.4382-4388, 1999.

[47]George Mokdsi, Margaret M., "Harding Inhibition of human topoisomerase II by the antitumor metallocenes," J.Inorg. Biochem, vol.83, no.2-3, pp.205-209, 2001.

[48]P.R.Chetana et al., "Synthesis, structure, DNA binding and oxidative cleavage activity of ternary (L-leucine/isoleucine) copper(II) complexes of heterocyclic bases," Polyhedron, vol.27, pp.1343-1352, 2008.

[49]J.D.Ranford et al., "Complexes of platinum(II) or palladium(II) with1,10-phenanthroline and amino acids," Inorg.Chimi.Acta, vol.,.304, pp. 38-44, 2000.

[50]P.Reddy et al, "Synthesis, structure, DNA binding and cleavage properties of ternary amino acid Schiff base-phen/bipy $\mathrm{Cu}(\mathrm{II})$ complexes," J.InorgBiochem, vol.105, pp.1603-1612, 2011.

[51]A. R. Chakravarty et al., "Photocleavage of DNA by copper(II) complexes," Indian Academy of Sciences, J.Chem.Sci., vol.118, no.96, pp.443-453, 2006.

[52]P.R.Chetana et al., "New ternary copper(II) complexes of L-alanine and heterocyclic bases: DNA binding and oxidative DNA cleavage activity," Inorg.Chim.Acta, vol.362 pp.4692-4698, 2009. 
[53]S. Arunachalam et al., "DNA binding and antimicrobial studies of some polyethyleneimine-copper(II) complex samples containing1, 10-phenanthroline and L-theronine as co-ligands," Polyhedron, vol.26, pp.3255-3262, 2007.

[54]D. Wang et al., "Synthesis, Characterization, DNA-binding Properties and DNA Cleavage of a New Ternary Copper(II) Complex with Mixed-ligands of Tridentate Schiff Base and 1,10- Phenanthroline," Chin. J.Chem. , Vol. 29, no. 2, pp. 259-266, 2011.

[55]S. Arunachalam et al, "DNA binding and antimicrobial studies of polymer-copper(II) complexes containing 1,10-phenanthroline and L-phenylalanine ligands," Eur. J.Med.Chemi., vol.44, pp.1878-1883, 2009.

[56]P.R.Chetana et al., "DNA binding and oxidative cleavage activity of ternary(L-proline)copper(II) complexes of heterocyclic bases," Polyhedron, vol.26, pp.5331-5338,2007.

[57]A.R.Chakravarty et al., "Synthesis, crystal structure, DNA binding and photo-induced DNA cleavage activity of (S-methyl-L-cysteine) copper(II) complexes of heterocyclic bases," J.Inorg.Biochem, vol.101, pp. 233-244, 2007.

[58]A.R.Chakravarty et al., "Synthesis, crystal structures, DNA binding and cleavage activity of L-glutamine copper(II) complexes of heterocyclic bases," Inorg.Chimi.Acta, vol.362, pp.1591-1599, 2009.

[59]B.Satyanarayana et al., "Synthesis and DNA cleavage properties of ternary $\mathrm{Cu}(\mathrm{II})$ complexes containing histamine and amino acids," Tetrahedron Letters, vol.47, pp.7311-7315, 2006.

[60]D.S.Pandey et al., "Synthesis, and characterization of ruthenium(II) polypyridyl complexes containing -amino acids and its DNA binding behavior," J.Organomet.Chem, vol.694, pp.3570-3579, 2009.

[61] A.S.Gaballa et al., "Synthesis, characterization and biological activity of some platinum(II) complexes with Schiff bases derived from, , and phenylenediamine" Spectrochim. Acta Part A vol.67, pp.114-121, 2007.

[62]Y.Huang et al, "Synthesis, characterization and DNA interaction of copper (II) complexes with Schiff base ligands derived from 2pyridinecarboxaldehyde and polyamines," Inorg.Chem.Commun., vol.13, pp.1421-1424, 2010

[63]V.C.Silveira et al, "Double-strand DNA cleavage induced by oxindole-Schiff base copper(II) complexes with potential antitumor activity," J.InorgBiochem, vol.102, pp.1090-1103, 2008.

[64]M.Wang et al., "DNA-binding, antioxidant activity and solid-state fluorescence studies of copper(II), zinc(II) and nickel(II) complexes 
with a Schiff base derived from 2-quinoline-3-carbaldehyde," Trans. Met. Chem, vol.36, pp.489-498, 2011.

[65]S.Eldin et al, "Synthesis, spectral, antimicrobial and antitumor assessment of Schiff base derived from and its transition metal complexes," Spectrochim.Acta Part A, vol.79, pp.1331-1337, 2011.

[66]Ahmed A. El-Sherif, Taha M. A Eldebss, "Synthesis, spectral characterization, solution equilibria, in vitro antibacterial and cytotoxic activities of $\mathrm{Cu}(\mathrm{II}), \mathrm{Ni}(\mathrm{II}), \mathrm{Mn}(\mathrm{II}), \mathrm{Co}(\mathrm{II})$ and $\mathrm{Zn}(\mathrm{II})$ complexes with Schiff base derived from 5-bromosalicylaldehyde and 2-aminomethylthiophene," Spectrochim. Acta Part A, vol.79, pp.1803-1814, 2011.

[67]M.S.Nair et al., "Synthesis, characterization and biological studies of $\mathrm{Co}(\mathrm{II}), \mathrm{Ni}(\mathrm{II}), \mathrm{Cu}(\mathrm{II})$ and $\mathrm{Zn}(\mathrm{II})$ complexes with with pyrral-Lhistidinate," Arab. J.Chem., vol.5, pp.179-186, 2012.

[68]Daqi Wang, "Synthesis, crystal structure and DNA-binding properties of a new copper (II) complex with L-valine Schiff base and 1,10-phenanthroline," J.Mol.Struc., vol.98, pp.57-63 2011.

[69] Tao Xu et al., "Synthesis, crystal structure, and DNA interaction studies of a mixed-ligand copper(II) complex of 1,10phenanthroline and a Schiff base derived from isoleucine Trans. Met.Chem, vol.36, pp.565-571, 2011.

[70]S.Yan et al., "DNA binding and cleavage activity of reduced amino-acid Schiff base complexes of cobalt(II), copper(II), and cadmium(II)," Trans Met.Chem, vol.34, pp.475-481, 2009.

[71]M.A.Neelakantan et al., "Spectral characterization, cyclic voltammetry, morphology, biological activities and DNA cleaving studies of amino acid Schiff base metal(II) complexes," Spectrochim. Acta Part A, vol.71, pp.1599-1609, 2008.

[72]B.Wang et al., "Spectra DNA-binding affinities of Copper(II), Nickel(II) complexes with a novel glycine Schiff base derived from chromone," Spectrochim. Acta Part A, vol.68, pp.912-917 2007.

[73]R.D. Gillard et al., "Preparation and characterisation of new oxovanadium (IV) Schiff base complexes derived from salicylaldehyde and simple dipeptides," Inorg.Chim.Acta, vol.305, pp.7-13, 2000.

[74]A.R.Chakravarty et al., "Iron(III) Schiff base complexes of arginine and lysine as netropsin mimics showing AT-selective DNA binding and photonuclease activity," J.InorgBiochem, vol.104, pp.477-484, 2010.

[75]A. R.Chakravarty et al., "Hydrolytic Cleavage of DNA by Ternary Amino Acid Schiff Base Copper(II) Complexes Having Planar Heterocyclic Ligands," Eur.J.Inorg.Chem., vol.7, pp.1440-1446, 2004. 
[76]T. M. Das et al, "Structural and DNA cleavage of sugar-derived Schiff base ligands and their dinuclear $\mathrm{Cu}(\mathrm{II})$ complexes," Carbohydrate research, vol.345, no.9, pp.1077-1083, 2010.

[77]A.R.Chakravarty et al.,"Synthesis, crystal structure, and nuclease activity of planar mono-heterocyclic base copper(II) complexes," J.InorgBiochem, vol.94, pp.171-178, 2003.

[78]S. Satyanarayana et al., "DNA-interactions of ruthenium(II) \& cobalt(III) phenanthroline and bipyridine complexes with a planar aromatic ligand 2-(2-fluronyl)1H-imidazole [4,5-f] 1,1Phenanthroline" J.Incl.Phenom.Macrocycl.Chem, vol.70, pp.187195, 2011.

[79]B. U. Nair et al., "Interaction of chromium(III) complex of chiral binaphthyl tetradentate ligand with DNA," Bioorg. Med. Chem., vol.14, pp.3300-3306, 2006. 